\title{
(Des)colonizações: de que contextos falamos quando falamos de educação à distância?
}

\author{
(De)colonializations: from which contexts we speak when talking about \\ distance education?
}

\author{
Leda Guimarãesi \\ Lilian Ucker Perottoii
}

\begin{abstract}
Resumo
Somos professoras da Universidade Federal de Goiás e durante os últimos cinco anos nos dedicamos à formação de professores em artes visuais em cursos de licenciatura à distância. Neste texto - organizado em três partes - compartilharemos reflexões que foram apresentadas durante o III Colóquio Internacional Educação e Visualidades, celebrado na Universidade Federal da Paraíba em dezembro de 2011, a partir de alguns 'incômodos' em relação a nossa experiência como docentes/coordenadoras de um curso à distancia. Para pensar quais e como se dão estes incômodos trabalhamos com a ideia simultânea de '(des) colonização', destacando algumas contradições, conflitos e deslocamentos provocados pela dupla percepção de colonizar/descolonizar a partir da nossa experiência com a educação à distância no contexto do ensino superior na UFG.

Palavras-chave: educação à distância, incômodos, (des)colonizações.
\end{abstract}

\begin{abstract}
We are teachers in the Federal University of Goiás and for the past five years we dedicated our efforts to visual arts teacher's education in distance teaching degrees. In this text - organized in three parts - we will share thoughts that were presented during the III International Colloquium of Education and Visualities, which took place at the Federal University of Paraiba in December 2011, departing from some 'disturbances' about our experience as professors/coordinators of a distance degree. In order to think about which are the disturbances and how they happen, we work with the double concept of '(de)colonialization', highlighting some contradictions, conflicts and displacements driven by a double perception of colonializing/decolonializing from the standpoint of our experience with distance education in the context of higher education at UFG.
\end{abstract}

Keywords: Distance Education, disturbances, (de)colonialization.

Una tarea colosal hacer el inventario de lo real. Amontonamos hechos, los comentamos, pero en cada línea escrita en cada proposición enunciada tenemos una impresión de algo inacabado. (FANON, 2009, p.

Nosso texto nasce de alguns 'incômodos' vivenciados durante nossa trajetória como docentes e coordenadoras nos cursos de Licenciatura em Artes Visuais ofertado na modalidade à distância pela Faculdade de Artes Visuais da UFG. São diferentes momentos de entrada nesse curso, uma de nós, desde as formulações dos projetos em 2005 e a outra a partir de 2009 via concurso público especialmente aberto para atender a esse novo contexto. Assim, nossos incômodos transitam não só por diferentes espaços 
de tempo, mas também por distintos espaços e tempos de formação acadêmica e profissional, e que neste texto unem-se com o objetivo para pensar nestas múltiplas experiências compartilhadas e alimentadas por discussões, debates, ideias concordantes e discordantes entre nós e a relação com o contexto da qual estávamos vinculadas quando nos propusemos a refletir sobre o tema deste artigo. Por isso, é importante destacar desde já, que este texto retrata experiências anteriores quando ambas assumiam a coordenação dos cursos/projetos ofertados pela faculdade de artes visuais na modalidade à distância. É possível, que se hoje, o foco deste artigo estivesse dirigido única e exclusivamente à nossas práticas docentes no curso á distancia, provavelmente nossas percepções sobre tais incômodos seriam outros.

Entre diálogos informais e experiências compartilhadas recebemos o convite para participar de uma mesa redonda no III Colóquio Educação e Visualidades, que seria realizado na UFPB em dezembro de 2011. A partir de aí e de algumas reuniões em função de tal evento, começamos a colocar sobre o papel nossos incômodos a partir da ideia da (des)colonização como espaço de múltiplos (des)encontros para pensar não só nas experiências vividas mas principalmente para situar tensões assim como contradições em relação ao contexto da qual estávamos inseridas.

Ao definirmos a ideia central que trabalharíamos para a apresentação passamos a considerar os seguintes questionamentos: estaríamos nós em meio ao olho do furacão do neo capitalismo utilizando a rede $w w w$ para colonizarmos a educação, a cultura, os ways of life do povo goiano? Seríamos novos bandeirantes com nossos carros de boi desmaterializados (tecnologias virtuais)? De que forma nos sentimos colonizados em relação às instâncias de fomento MEC e especialmente ao FNDE (verbas) e a CAPES (regulamentações) que na maioria das vezes nos impunha as receitas de bolo EAD?

A palavra (des)colonização passa então a ser trabalhada com parênteses, indicando oscilações entre estratégias e táticas no processo da implementação e desenvolvimento desse curso. Os conceitos de estratégia e tática, tomados de Michel de Certeau (1990), orientam nossa leitura quando pensamos nos incômodos. A distinção entre os dois conceitos reside principalmente no tipo de operação que se pode efetuar. Enquanto as estratégias são capazes de produzir e impor, as táticas só permitem utilizar, manipular e alterar algo. A primeira é exterior, enquanto a segunda opera na interioridade, a nosso ver, nas relações intestinas:

[...] a ação calculada que é determinada pela ausência de um próprio. Então nenhuma delimitação de fora lhe fornece a condição de autonomia. A tática não tem por lugar senão o do outro. E por 
isso deve jogar com o terreno que lhe é imposto tal como o organiza a lei de uma força estranha. (p.99).

No decorrer da escrita iremos apontando contradições, conflitos e deslocamentos provocados pela dupla percepção colonizar/descolonizar a partir da nossa experiência com a educação à distância no contexto do ensino superior na UFG. Utilizando então esse guarda chuva dividimos o texto em três momentos: no primeiro momento 'Primeiras contextualizações: puxando o estilingue para trás' adotamos uma perspectiva histórica para situar o contexto da educação à distancia e o impacto da expansão do ensino superior. Aliada a isso, contextualizaremos a situação dos cursos de licenciatura em artes visuais, mais especificamente os de artes visuais, na modalidade ead apresentando algumas fissuras causadas pela implantação desse curso na universidade de cal e pedra. Já no segundo momento e a partir da pergunta 'Que incômodos e percepções emergem da nossa experiência?' lançamos nosso olhar para as tentativas de estratégias de (des)colonização em relação aos conflitos da proposta curricular, das ações docentes e também do ambiente virtual de aprendizagem. Nesta parte do texto incluímos 'nossas vozes' dando destaque a experiências e percepções individuais. Finalizamos no terceiro momento 'Entre lugares, entre os incômodos' tentando refletir sobre a questão que intitula o artigo: de que contextos falamos quando falamos de educação à distância? Ou seja, em que concepção de universidade situamos a nossa prática?

\section{Primeiras contextualizações: puxando o estilingue para trás}

Este termo é uma expressão do designer Aloísio Magalhães citado por Ana Mae Barbosa como analogia para a importância da história: "A metáfora de Aloísio Magalhães para explicar a importância da História é de grande precisão. Quanto mais puxamos a borracha do estilingue para trás mais longe lançaremos a pedra para frente." (BARBOSA, 2010). Assim, para contextualizar a nossa atuação no ensino superior ofertado na modalidade à distância vamos puxar um pouco a borracha do estilingue para trás, e lembrar do atraso histórico que o Brasil tem em relação aos outros países da América Latina na oferta de ensino superior (CUNHA, 2000).

A dominação da Igreja Católica e o descaso da corte portuguesa em relação a sua colônia tiveram como consequência que, o primeiro curso superior fosse criado somente em 1808. As primeiras universidades surgiram no início do século XX: A Universidade Livre de Manaus em 1909, a Universidade do Rio de Janeiro em 1920, em 1927 a Universidade de Minas Gerais e a Universidade de São Paulo em 1934. Durante muito tempo Rio de Janeiro e São Paulo foram às cidades para onde se mudavam os jovens da elite interiorana (com exceções) em busca de uma formação universitária. Outra parte 
significativa da juventude (geralmente classe média e pobre) procurava sua formação em seminários religiosos, herança e fruto ainda da forte estrutura educativa dos jesuítas no período colonial.

Como dissemos, buscamos situar pontos de ausência e atraso para tentar compreender melhor a pergunta que dá título a esse texto: "De que contextos falamos quando falamos em educação à distância?" e a partir desta gerar outras questões: que práticas/estratégias de (des)colonização identificamos em nossa experiência com a educação à distância? Por exemplo, é importante ter noção de que o quadro da educação "superior" só começa a mudar na década de 60 , quando se criam universidades públicas em quase todos os estados do Brasil. De lá pra cá, a rede instalada não tem atendido a demanda por educação de uma faixa mais larga da população, que agora, também almeja (e necessita) entrar e estar na universidade. Também é importante pensar que o próprio termo "superior" é carregado de sentidos postos em termos de distinção e já carrega em si mesmo uma exclusão presente nos processos de colonização, quando o conhecimento é usado para forjar o "ferro" ${ }^{1}$ do colonizador.

Conforme o relatório sobre educação relatado pela organização para cooperação e desenvolvimento econômico (OCDE), divulgado em setembro do ano passado, mostra que o país está na $38^{a}$ colocação entre 40 nações quando se trata de ensino superior. Apenas $11 \%$ da população entre 25 e 64 anos de idade chegou a um nível mais elevado de estudos. No entanto, os dados do censo 2010 realizado pelo Instituto Brasileiro de Geografia e estatística (IBGE) sugerem que houve um crescimento no número de brasileiros com terceiro grau na última década. A porcentagem total aumentou de $4,4 \%$, em 2000 para 7,9\% em 2010. Os estados com mais graduados são, respectivamente, Distrito Federal $(17,6)$, São Paulo $(11,7)$ e Rio de Janeiro $(10,9)$. No estado de Goiás, cena da nossa ação, essa taxa foi de apenas 7,75\%. Espera-se que até 2020, certamente, essas taxas possam aumentar para que o Brasil fique perto do nível recomendado que é de $31 \%$ da população com ensino superior. $\mathrm{Em}$ uma reportagem digital a pesquisadora Elisabeth Balbachevsky alerta que esta situação é fruto do baixo desempenho que, apresentamos em relação ao ensino médio. Apenas menos da metade dos jovens com idades entre 15 a 17 anos está no ensino médio. A maioria deles ou não terminou a educação primária ou abandonou os estudos. Ao contrário de outros países emergentes, explica Balbachevsky, a "a população jovem que consegue terminar o ensino médio no Brasil [e que teria condições de avançar para o ensino superior] é muito pequena". A pesquisadora presta especial atenção para o fato de que $75 \%$ da oferta de vagas em níveis mais elevados estão em instituições privadas,

\footnotetext{
${ }^{1}$ Ferro aqui no sentido da ferramenta com a logomarca do dono para marcar gado, também usado para marcar escravos.
} 
afirmando que a questão financeira afeta diretamente o acesso na Universidade. Além disso, explica que "vamos ter que ser muito mais ágeis, pois infelizmente perdemos quase um século sem investimentos na Educação".

Compartilhar esses dados torna-se necessário para destacar a importância da política de expansão do ensino superior. Através da educação à distância, especialmente a partir do ano de 2005, quando foi publicado o Decreto $n \circ 5.622$, que estabelece as características, a sua forma de organização, modalidades, avaliação, formas de credenciamento e atividades de sala de aula obrigatória (Brasil, 2005). Foi neste mesmo ano, que o governo brasileiro inaugurou a Universidade Aberta do Brasil (UAB), criado pelo Ministério da Educação em parceria com entidades e empresas estatais no âmbito do plano de desenvolvimento da educação (PDE); o plano foi destinado a democratizar o ensino superior no Brasil. Também em 2005 foi lançado o programa Prolicenciatura que tinha como objetivo atender professores que atuavam nas escolas com o ensino de arte, mas que não possuíam formação especifica na área.

Depois do Prolicenciatura e da UAB nos chega o Plano Nacional de Formação dos Professores da Educação Básica - PARFOR - programa nacional implantado pela CAPES, em regime de colaboração com as Secretarias de Educação dos Estados, do Distrito Federal e dos Municípios e com as Instituições de Ensino Superior (IES), para oferta de cursos na modalidade à distância, no âmbito do Sistema UAB, para professores ou profissionais em exercício nas redes públicas de educação (http://www.capes.gov.br/educacao-a-distancia/parfor-a-distancia.). Ou seja, outro programa governamental, preocupado com formação de professores que não reeditavam os propósitos dos programas anteriores e muitas vezes, recaiam como ofertas de qualificação para um mesmo público: o professor da educação básica. Conversamos com professores, nossos alunos do Prolicenciatura, que, prevenidos, já tinham realizado suas inscrições na Plataforma Freire, caso não lograssem êxito no curso que estavam fazendo. De qualquer maneira, o anúncio da oferta da nossa Licenciatura no PARFOR gerou um capital político de mais de 1.000 interessados em cursar a nossa Licenciatura. Capital que foi utilizado simbólica e concretamente nas reivindicações "conseguir vagas" e "melhores condições de trabalho" em nosso dia a dia.

No site eletrônico do IX Seminário Nacional de Educação a Distância (2013) realizado em junho de 2013, na cidade de Brasília, o presidente da ABED Frederick M. Litto mostra dados interessantes, sobre o impacto que a educação à distância está provocando no contexto do país. Litto explica que

Hoje, quase $20 \%$ dos seis milhões de universitários no país estudam à distancia em cursos reconhecidos pelo MEC. Em apenas 
interdisciplinaridade e a integração entre as artes, a educação e a mídia (intermediação). Brasil atingiu a marca de 300.000 alunos matriculados; no ENADE, exame nacional do MEC (ministrados aos formandos a cada ano), aqueles que estudaram a distância tiveram média de notas superiores às dos alunos do ensino convencional. Portanto, são indicadores de que brasileiros estão se adaptando eficazmente à $E A D$, razão pela qual a modalidade deve merecer alta prioridade no planejamento das metas nacionais a serem atingidas para a criação de uma força de trabalho para suprir a precariedade do ensino, em todos os níveis, usando critérios internacionais, para que o Brasil se iguale àqueles que crescem com os avanços da EAD. ${ }^{2}$

Esses dados gerais afetam diretamente a área de artes. Conforme Medeiros (2010) o país tem um total de 607 cursos superiores credenciados na área de artes (dados de 2010 do $E_{-M E C}^{3}$ ). Dos 607 cursos/habilitações 189 são de Música, 185 de Artes Visuais, 97 de Artes, 43 de Cinema e Audiovisual, 34 de Artes Cênicas, 33 de Teatro e 26 de Dança. No entanto, Medeiros (2010) explica que o número de cursos é insuficiente para atender a necessidade de profissionais para o exercício docente nessas áreas, pois "se presume que cerca de $1 / 3$ (pouco mais de 200) são licenciaturas", ou seja, a maioria dos cursos de artes não prepara para a docência, e percebemos que cada vez mais, aumenta a demanda por professores para atuar tanto em contexto formal quanto não formal.

Embora ainda insuficientes para atender a demanda por mais e melhores profissionais para a docência em artes, vejamos que os cursos na área de artes ofertados na modalidade EAD são majoritariamente licenciatura, com a explícita tarefa de formar para a docência. O que não exclui a formação artística, estética e cultural. Outro ponto a ser destacado, é que estes cursos já nascem na especificidade de suas linguagens, a saber Licenciatura em: Artes Visuais, Música, Teatro, Dança. Isso significa dizer que esse foco das universidades públicas na formação de professores de arte em suas linguagens específicas está consoante ao momento político das reivindicações da categoria "arteeducadores" que ao rejeitar a polivalência, entende a necessidade de uma formação verticalizada embora aberta aos intercâmbios inter e transdisciplinares e para vivências de interterritorialidade de campos. Exemplo dessas possibilidades podem ser encontradas no livro "Interterritorialidade - mídias, contexto e educação" resultado do projeto Interterritorialidade, realizado em 2005, que reuniu no SESC Pinheiros, em São Paulo, artistas, educadores, criadores, produtores, críticos e público para discutir a questão da relação entre a arte, educação, os meios tecnológicos, contextos socioculturais e suas fronteiras contemporâneas, abordando temas como a interculturalidade,

\footnotetext{
${ }^{2}$ http://abed.org.br/senaed2013/imagens/apresentacao.jpg

${ }^{3} \mathrm{O}$ e-MEC é um sistema eletrônico de acompanhamento os processos que regulam a educação superior no Brasil.
} 
interdisciplinaridade e a integração entre as artes, a educação e a mídia (intermediação).

O título do livro remete exatamente aos limites e aos territórios multidisciplinares pelos quais navegam a arte e a estética na atualidade. Segundo as autoras:

Diálogos cada vez mais intensos vêm configurando uma nova cartografia cognitiva, caracterizada por colaborações entre diferentes territórios e domínios, que provocam interrelacionamentos entre disciplinas como história da arte, estética, teoria dos meios e muitas outras. O livro vem iluminar o debate sobre o tema, constante nos meios acadêmicos e escolares (BARBOSA e AMARAL, apresentação do livro, 2008).

Essa nossa reflexão se atém ao contexto das universidades públicas, pois sabemos que existem universidades privadas ofertando ainda a formação polivalente da "educação artística". Na Universidade Federal de Goiás, enquanto o curso presencial forma uma média de 20 alunos ao longo 4 anos, os cursos na modalidade a distância implementados em 2007/2008 já formaram em um espaço de tempo de 4 anos 350 novos professores de artes visuais (UAB $1-250$ + Prolicenciatura -100). Dentro de pouco tempo formará mais 200 docentes.

O argumento de que estamos utilizando a lógica do governo e apostando em números é algo que não nos cabe. Podemos pensar se formar essa quantidade de professores é ceder ao canto da sereia do neoliberalismo, e que essa expansão numérica é também uma ferramenta de colonialismo cultural. Para nós, a oportunidade de formar um grande número de professores para o ensino de artes visuais era muito significativo. O dado numérico neste caso converte-se em nossa perspectiva, um dado de resistência, ou como no lema da arte educadora ativista de arte pública Lilian Amaral: "Ocupar é resistir!".

O sistema de oferta desses cursos a distância oferecia dentre outras coisas: (a) a possibilidade de descentralização de espaços alcançando cidades interioranas, em que a falta de professores para as aulas de artes era ainda maior do que na capital (b) colocação em circulação de uma produção teórica através da publicação de textos de professores e especialistas da área, (c) formação de parcerias com outras universidades possibilitando a criação de uma rede colaborativa (d) facilitar a aprendizagem de informação e tecnologias de comunicação, equipando-nos com máquinas modernas, nos laboratórios das tecnologias da informação e comunicação e (e) construir uma equipe interdisciplinar que poderia atuar, não só a pedagógica, também no design instrucional e nas tecnologias de apoio. Estas possibilidades também trouxeram a necessidade de diversas mudanças nas estruturas da universidade e dos grupos onde estávamos imersas. 
Aceitamos o desafio com muitas dúvidas, incertezas, mas também com questionamentos: Com qual conceito de "distância" iríamos trabalhar? Como seria dar aulas das disciplinas práticas (ateliers) em suas diversas linguagens nesse contexto virtual? Seria necessário modificar os estilos, os modos de acesso e de construir os saberes nesse novo ambiente? Como oferecer uma formação de qualidade se mesmo o curso já existente no formato presencial não havia superado as deficiências de infraestrutura e de estrutura curricular? No entanto, nós não tínhamos noção (e seria impossível ter naquela época) que outros desafios ou tensões viriam no bojo da nossa prática. Na medida em que o curso avançava, surgiam conflitos em todos os lugares: com estudantes, com a própria Faculdade que abrigava o curso, com outros cursos, com a universidade em si, e com o MEC e a CAPES, com suas regras de regulamentação para a oferta desses cursos EAD. Conflitos também com professores e equipe técnicoadministrativa que foi se incorporando e construindo junto essa nova realidade. Para muitos, isso pode ser sinal de fraqueza, mas, não existe educação sem conflito. 0 conflito é o espaço dialógico para construirmos o conhecimento. Dos conflitos emergentes, podemos afirmar que a educação à distância provocou fissuras no tecido da universidade (GUIMARÃES, 2008, 2010a, 2010b, 2011) gerando incômodos, dado que colocava em questão um conjunto já estruturado. Para nós, o ensino convencional ou presencial das universidades está enquadrado numa arquitetura de pedra e cal: edifícios, aula, bibliotecas, corredores de circulação, salas de professores, auditórios, etc. A entrada da EAD nessa "arquitetura" rompe com uma estrutura e a educação a distância passa a desmaterializar a ideia de universidade. Do mesmo modo que os encontros presenciais, sejam frequentes ou mensais, em sua maioria ocorrem em lugares distantes dessa "universidade de pedra e cal" com seus atores e ritos institucionalizados. Os espaços de ensino/aprendizagem, de circulação de afetos, configuram-se no AVA Ambiente Virtual de Aprendizagem, promovendo novos tipos de relações pedagógicas.

\section{Que incômodos e percepções emergem da nossa experiência?}

Nesse relato, várias são as referências aos processos colonizadores do século 18 em relação às ações que desenvolvemos. Refletimos sobre como estratégias de expansão e mapeamentos, relatos de viagens, gráficos, escolhas nos desenhos curriculares e mecanismos de mediação entre atores podem ser entendidos como analogias a estratégias coloniais. Como estas ferramentas do conhecimento moderno, preciso, ilustrado, continuam ordenando, certificando e legitimando o ensino superior (inclusive a nomenclatura) e o que interessa ser reconhecido como válido. Entretanto, as reflexões que vão para um lado, logo puxam para o outro. 


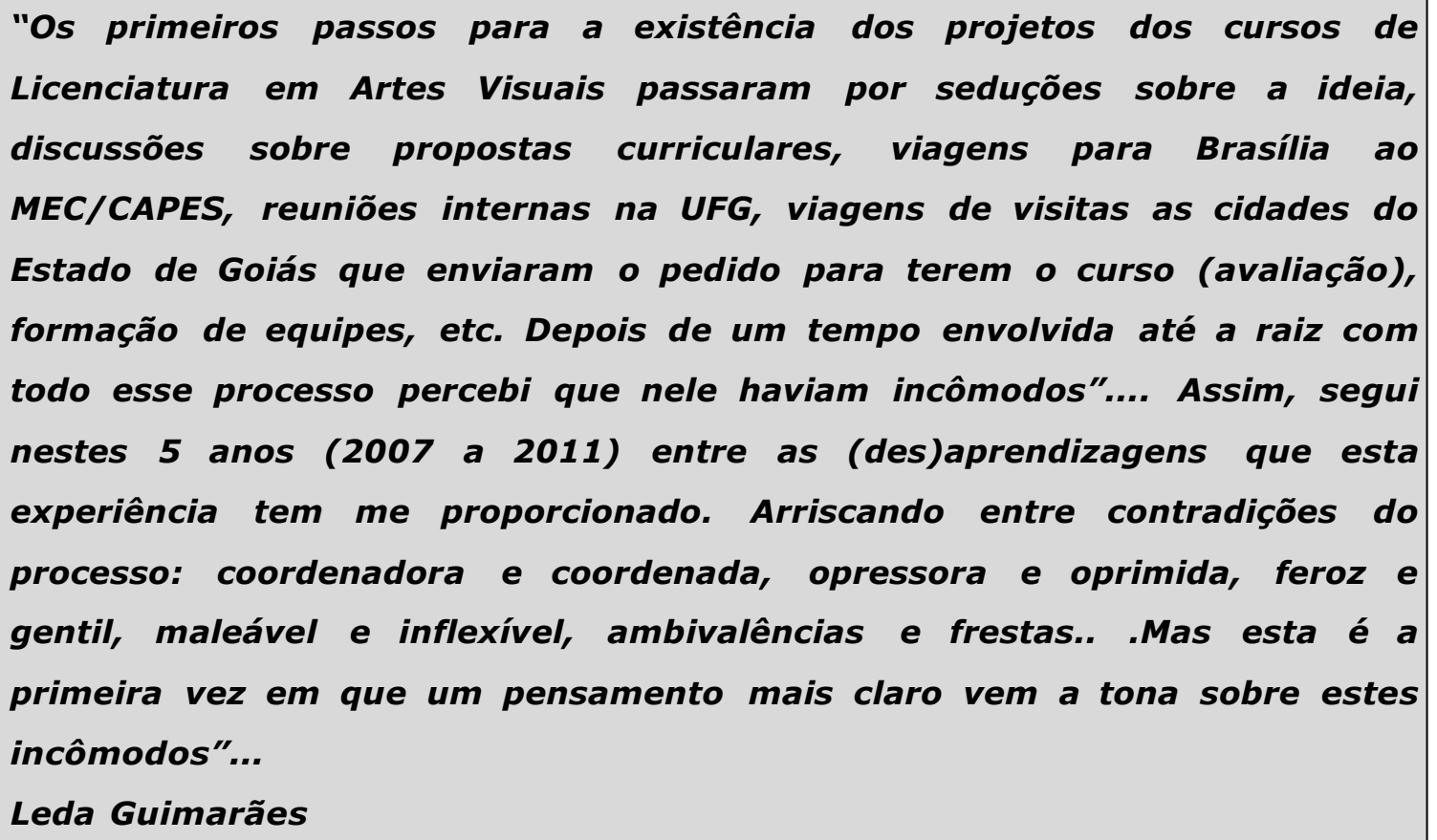

Aqui, se instalam os primeiros conflitos entre a sedução da proposta do governo que acenava financiamento para a formação de professores na modalidade ead e a condição de ignorância e desconhecimento sobre o que se propunha. Seduções por parte do governo federal que prometia a ampliação de vagas para professores nas universidades públicas federais via concurso publico. Sedução com o financiamento de condições físicas e tecnológicas para o trabalho. Sedução com as bolsas para pesquisa, que "complementavam" os maus salários, bolsas para tutores que viriam atuar em conjunto com os professores da casa nesse novo contexto. Muita coisa aconteceu. Não podemos deixar de mencionar que durante o período de 2009 a 2011, passamos a trabalhar numa equipe com 7 professores efetivos. Vagas que foram abertas exclusivamente para a educação à distancia. Laboratórios foram montados, máquinas atuais chegaram, mecanismos de web conferência, hospedagem na rede da CAPES para realizar transmissões online, dinheiro para a produção de material didático (objetos de aprendizagem) e muitas outras coisas que beneficiaram a Faculdade de Artes Visuais bem como os pólos em que eram ofertados os cursos. Muita coisa não aconteceu: instalação para o curso de artes visuais nos pólos sempre precária, relação irrisória de vagas docentes em relação à quantidade discente, condições de trabalho instáveis, dentre outras promessas e necessidades que não foram cumpridas. Entre prometido cumprido e não cumprido, muita água correu por debaixo dessas seduções. Assim como fomos seduzidos, era preciso seduzir a outros, muitos outros. Atrair gente nova, propor parcerias, intercâmbios, mudar posturas preconceituosas via desafios de uma imersão experiencial como professores ou tutores. 
"Interrompi meu doutorado na Universidade de Barcelona para assumir uma vaga como professora de um curso de formação de artes visuais via educação à distancia. Até então, não podia imaginar o que me esperava. Vinha influenciada por uma série de experiências vividas e compartilhadas durante minha participação em um grupo de inovação docente da Universidade de Barcelona chamado Indaga't. o grupo formado por professores de diversas áreas do conhecimento tinha como objetivo não só compartilhar experiências da docência, mas também ou principalmente promover aprendizagens significativas entre os alunos com base na autonomia intelectual e na criatividade. No primeiro projeto, utilizamos uma plataforma digital como ferramenta para promover estas aprendizagens. A partir de tal experiência cheguei a Goiânia carregada de inquietações. Um dos questionamentos era pensar se todo bom professor presencial é (ou pode ser) um bom docente em um entorno virtual (Bautista et al, 2006).

\section{Lilian Ucker}

Uma das questões que alimentaram a nossa trajetória era tentar compreender, ora o que nos constituía como docentes, independente da modalidade da oferta do curso, e ao mesmo tempo, por meio da experiência com as especificidades da modalidade, entender que era necessário uma aprendizagem para lidar com o meio. Tem havido uma preocupação na formação tecnológica de novos docentes para atuarem nessa modalidade. No entanto, a importância da formação metodológica, científica e de mediação comunicativa, assim como a questão pedagógica tem sido desafiadora e requer muito mais formação científico-cultural dos docentes do que a expertise no manuseio de equipamentos. A experiência colaborativa do grupo indaga't pode ser um exemplo dessa formação em sentido mais amplo e aponta para uma experiência dificilmente vivenciada nos cursos presenciais. E podemos dizer que os "cursos ead" não teriam sobrevivido, ou mesmo iniciado o seu processo, sem um forte trabalho de equipe e colaboração, que marca as experiências das nossas vivências e desaloja os procedimentos autocentrados das dinâmicas até então presentes nos cursos presenciais.

Os mapas... Era tão importante desenhá-los, marcar no mapa do estado os polos que íamos "conquistando"... pontos circulados mostrando as cidades nas quais a Faculdade de Artes Visuais estava ofertando a Licenciatura em Artes Visuais na modalidade EAD. Quase toda a equipe tinha essa preocupação. Dava orgulho ver os 15 pontos demarcados, 9 cidades da UAB e 6 do Prolicenciatura. E essa foi uma referência visual muito citada nos textos que escrevi. Como em uma competição do jogo batalha naval, nos orgulhávamos também de sermos uma das unidades com mais "territórios" conquistados. Imagina, logo nós de artes visuais, nos igualávamos em número de polos ao pessoal da Biologia.

Leda Guimarães 
Os mapas fazem parte do imaginário da expansão (esta também visual) do ocidente. E parecia ser o nosso caso. No entanto, no decorrer do processo as tantas viagens para encontros presenciais foram mudando a configuração organizada desse mapa inicial. Mudanças que inclusive nos causaram problemas operacionais e institucionais e mais uma vez colocavam em cheque o que já estava instituído para uma educação de paredes fechadas e cadeiras fixas. Por exemplo, se fossemos mapear as cidades onde os nossos estudantes residiam, os pontos marcados no mapa multiplicavam-se. Isso gerava demandas não previstas, como a dificuldade de determinados alunos atenderem as aulas presenciais nos polos e mais tarde, de também fazerem o estágio curricular obrigatório nas escolas de uma cidade que não era a sua. Isso gerava impasse, pois enquanto tentávamos solucionar essas situações, a orientação da pró-reitoria era tipo "dura lex sed lex", ou seja, os alunos tem que frequentar aulas e demais atividades nas cidades pólos em que se inscreveram. Racionalmente sabíamos que esta era a solução mais razoável (para a universidade), mas, o humano tem seus atravessamentos,

\begin{abstract}
Porque con frecuencia los mapas se van trazando a partir de las historias personales, pues, si es verdad que el origen del mapa se encuentran en la tempranísima necesidad humana de trasladarse de un lugar a otro y que salvaguarda el regreso a casa, no es menos cierto que las historias de vida - al igual que los recorridos míticos de determinados grupos, sobre todo de aquéllos forzados por determinadas circunstancias a abandonar su lugar de origen van modificando las lecturas consuetudinarias de las cartografías (ESTRELLA DE DIEGO, 2008 p. 41).
\end{abstract}

Assim, os mapas iam sendo redesenhados, noções de centro e periferia se alternavam, mapas de afetos iam sendo configurados. $E$ as rotas que percorríamos não eram unidirecionais. Privilegiamos em nossas muitas atividades a construção de cartografias que de maneira geral, desvirtuavam os mapas já traçados.

Outro marco desse processo foi a questão da auto-representação que assumimos como algo maior do que as nossas subjetividades. Além das faixas para demarcar o território, mandamos fazer camisas, e usávamos ainda de outras estratégias de identificação da nossa matrix.

Leda Guimarães

A 'mímica' (BHABHA, 1998) "como uma das estratégias mais ardilosas e eficazes do poder e do saber coloniais" foi outro conceito chave quando decidimos trabalhar com o tema da (des) colonização. Para o autor, a mímica

é também o signo inapropriado, porém uma diferença ou recalcitrância que ordena a função estratégica dominante do poder 
colonial intensifica a vigilância e coloca uma ameaça imanente tanto para os saberes 'normalizados'quanto para os poderes disciplinares (BHABHA, 1998, p. 130).

Estrella de Diego (2008) ao refletir sobre o caráter e configuração das estratégicas coloniais nos menciona a afirmação do explorador capitão Bougainville ${ }^{4}$ de que "cada frances fuera de casa es Francia". Para a autora essa é afirmação faz parte da "...estratégia básica de toda política colonial: diseñar el planeta completo como un todo idéntico" (p. 15). Em nossos deslocamentos presenciais nas viagens aos polos, era assim que nos sentíamos, representando a Universidade Federal de Goiás, o centro da nossa ação desse empreendimento de expansão do conhecimento. Éramos um, mas éramos ao mesmo tempo o todo. Muitas outras vezes, representávamos um sistema ainda mais centralizado, ou seja, o próprio governo federal, de cujo sistema as universidades públicas federais fazem parte. Também não podemos negar que o exercício de empoderamento nos seduzia, pois o curso de Licenciatura em Artes Visuais na modalidade EAD, de forma não "tão suavemente", ia aos poucos aparecendo aos olhos das sub macro estruturas: da própria unidade de ensino ao contexto CAPES, representando aqui o topo da hierarquia institucional.

..."Professora, eu sou aluna da UFG ou do polo de Catalão?

Eu devo seguir as normas do polo ou da UFG?"...

Era difícil para os alunos compreender que o polo era/é uma extensão da universidade. Em muitos momentos eles relatavam que não se sentiam alunos da UFG. O primeiro grupo a graduar-se pela Universidade Federal de Goiás no curso de licenciatura em artes visuais à distancia não chegou a realizar matricula online. Suas matriculas eram realizadas no inicio de cada semestre via papel e via polo no qual estavam vinculados.

Cria-se com a educação a distancia 'outra' ideia e experiência de universidade.

Lilian Ucker

A dúvida da aluna sobre seu pertencimento revela as fraturas da universidade de pedra. São vários os conflitos. Primeiro, o polo (que podia ser um edifício ou apenas uma sala com uma placa identificando UFG) é mais palpável que a matriz que ela aluna, nunca frequentou (pelo menos naquele início). Não tem a vivência da sede, mas tem os seus preceitos que se chocam com o de outras autoridades locais: a secretaria de educação

\footnotetext{
${ }^{4}$ Louis Antoine de Bougainv (1729 - 1811) foi um oficial, navegador e explorador francês a serviço do rei Luís XV. Suas narrativas sobre o Haiti ajudaram a construir a ideia do exótico paraíso terrestre e influenciou muitos viajantes, incluindo o pintor Gauguin.
} 


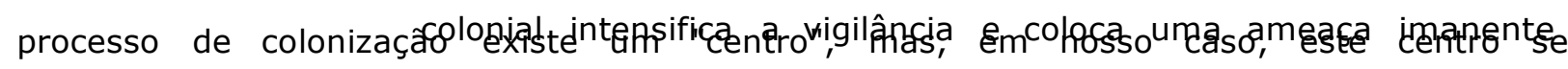
encontra outros centros, e a centralidade da autoridade da universidade torna-se difusa e compartilhada por outros atores e também outros espaços. Isso significou novas leituras e rearranjos de práticas e discursos para reiterar o lócus do conhecimento que se desintegrava na "modalidade a distância".

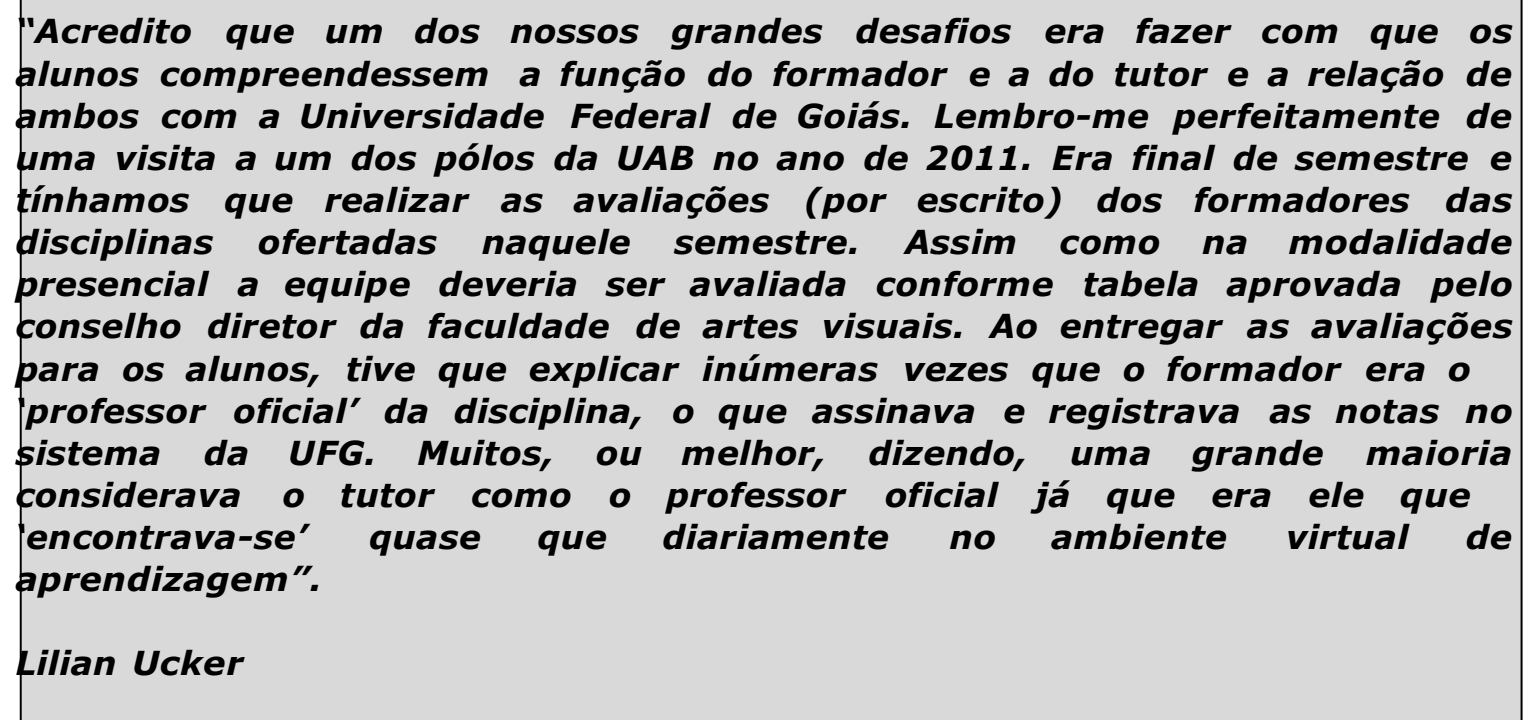

Se "cada francês fora de casa representa a França" (citado anteriormente) qual seria o lugar dos atores "não oficiais" da UFG, mas reconhecidos pelos estudantes como os "que representam a matriz"? Numa operação contaminadora (transgressora) os alunos donos de posições legitimas na instituição impregnam de legitimidade os atores "não oficiais" que "estão" nessa mesma instituição. Tutores entendidos como professores, bolsistas como secretárias e técnicos, que desenvolvem diversas funções na estrutura que fazem funcionar a oferta de cursos à distância. E não só a educação à distância, mas também afetam positivamente a estrutura dos já existentes cursos "presenciais" trazendo mudanças, infraestrutura tecnológica, para as unidades que abrigam os referidos cursos. Podemos exemplificar o uso do moodle que atende aos cursos a distância, e que passa também a ser utilizado pelos professores da modalidade presencial. Muitas outras ações poderiam ser citadas como promotoras de atravessamentos: ações educativas, cursos extracurriculares abertos à comunidade, viagens. Uma série de movimentos, que por mais que existisse um documento explicando as funções de cada ator, a vivência da polifonia de vozes, que juntas, desestabilizam posições de quem é quem neste cenário. 


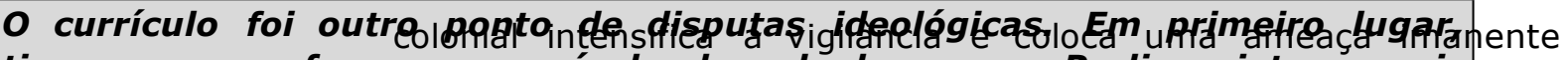
tivemos que reformar o currículo desenhado para o Prolicenciatura, pois segundo as orientações, a proposta da UAB seria específica de cada universidade e sendo assim, o currículo da EAD deveria dialogar de perto com o currículo do curso presencial já existente. No entanto, naquela altura, já tínhamos vários desejos de mudanças para a estrutura curricular do curso presencial. Como fazer? Como nos aproximar e ao mesmo tempo nos diferenciar? Aquele era o momento de propor mudanças de acordo com as inquietações conceituais que já nos acompanhavam, mas, tivemos que prestar atenção em alguns detalhes, como por exemplo: com que concepção de arte nossos futuros estudantes estavam mais familiarizados? Muitos deles já eram professores de artes nas escolas, que concepções e práticas tinham? E nas suas próprias vidas?

Leda Guimarães

São muitas as desconstruções da noção de currículo como um documento regido por neutralidades. Hoje, compreendemos que currículo é produto de um processo de conflitos culturais dos diferentes grupos de educadores que o elaboram (LOPEZ, 2006), poderíamos acrescentar, e também daqueles que fazem o currículo existir na prática, com as derivações e significações cotidianas. Para Silva (2005) o currículo é sempre resultado de uma seleção de um universo mais amplo de conhecimentos e saberes. Assim, também vivenciamos os deslocamentos entre um currículo um dia apresentado em um projeto para ser julgado e aprovado, e aquele currículo construído no dia a dia das nossas incertezas e expectativas. Os conflitos de seleção e exclusão na construção do desenho curricular foram muitos. Mas, ainda maiores, foram os conflitos de dar vida aquela proposta. Expectativas, planos e enfrentamentos, mudanças de estratégias, ousadias, fizeram movimentar uma força motriz que alimentavam uma "outra universidade", ou seria "The same old shit"?

o núcleo de história da arte foi palco de muitos atritos.. Manter a estrutura linear das disciplinas organizadas em sucessivos tempos históricos foi uma necessidade para atender ao diálogo com a estrutura do presencial. No entanto, esperávamos que quando os conteúdos fossem escritos, teríamos chance de problematizar as concepções de "grande arte" com suas narrativas hegemônicas. Para contrabalançar propusemos outras disciplinas que oferecessem perspectivas diferentes da hegemônica tais como: "Arte e Cultura Popular"; "Matrizes Culturais da Arte Brasileira", na qual o nome matrizes foi criticado, "Estéticas Afro asiáticas", um farto material de História da Arte Brasileira, além das disciplinas de Antropologia Cultural, Poéticas Visuais Contemporânea e Cultura Visual. Um pé lá e outro cá....

Leda Guimarães 


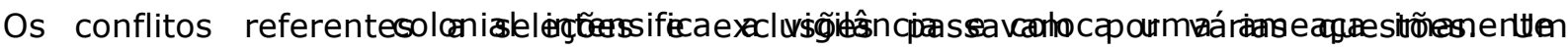
currículo não pode ser pensado como um receituário ideal, já que fatores humanos, técnico-burocráticos, ideológicos podem ou deveriam estar juntos na elaboração de uma proposta. O fato é que no nosso caso, os conflitos presentes no momento da elaboração, ficaram visíveis ao longo do processo de implementação do curso. Conseguir autores que escrevessem sobre História da Arte (da Pré-História a Arte Contemporânea) com outra perspectiva foi uma dificuldade. Os primeiros textos praticamente repetiam os livros de História da Arte que já conhecíamos. Investimos na formação de tutores para que pudessem fazer uma mediação problematizadora, questionando os pressupostos hegemônicos dessa disciplina. No entanto, muitas vezes esses pressupostos foram reforçados, seja pela própria formação dos professores e tutores, seja pela resistência dos próprios estudantes mais propensos ao encantamento das "belas artes", dos "grandes gênios", do que ao exercício reflexivo que tentávamos propor.

\section{Entre lugares, entre os incômodos}

Assim, entre estratégias de colonização entranhadas nas operações educativas e táticas pedagógicas que procuravam subverter as estruturas, fomos nos constituindo, entre lugares, entre estes incômodos. Uma coisa de um, uma coisa de outro: nossos espaços não são nem centro nem periferia, mas algo que transborda, abriga e alimenta as relações institucionais que configuram o acesso ao "ensino superior".

Acreditamos nos hibridismos, mas também na ironia, não só como prática consciente e constante de dúvida (RORTY apud AGUIRRE, 2010), mas como posicionamento para poder estar entre estes lugares, entre estes incômodos. De acordo com Souza (2004): Homi K. Bhabha "valoriza o hibridismo como elemento constituinte da linguagem, e, portanto da representação" (p. 114), o que implica na impossibilidade de se pensar uma descrição ou discurso autêntico sobre o sujeito colonizador ou colonizado. Assim, qualquer tentativa de representação é híbrida por conter traços dos dois discursos.

Sabemos dos perigos e concordamos que é necessário rever as bases desse "contrato invisível", dos perigos de colonização de mentes e corpos, do excesso da carga de trabalho. Isso já vem acontecendo com o avanço das tecnologias mesmo nos cursos presenciais, o aumento dos casos de LER, (lesão por esforço repetitivo) e muitas doenças de fundo emocional. No entanto, é impossível negar os desalojamentos provocados pela educação à distância em nossas vidas docentes. Todos afetamos e todos fomos afetados. Voltando a nossa aventura colonial, no lugar de dizer "represento, portanto sou a França" podemos recusar este discurso colonizador e deixar-se fracionar e poder dizer : "tenho algo de França em mim". 
colonial intensifica a vigilância e coloca uma ameaça imanente

\section{Referências}

AGUIRRE, Imanol. Questões Multiculturais para o Ensino da Arte. In: Módulo 6. Universidade Federal de Goiás. FUNAPE/CEGRAF. Goiânia, 2010.

BARBosA, Ana Mae. Artes e Culturas Visuais. Anais do XX CONFAEB. Faculdade de Artes Visuais da UFG. 2010.

BARBOSA, Ana Mae e AMARAL, Lilian. Interterritorialidade - mídias, contextos e educação (Editora Senac São Paulo e Edições SESC SP),São Paulo. 2008.

BAUTISTA, Guillermo; BORGES, Federico; FORÉS, Anna. Didática universitária em entornos virtuales. Narcea Ediciones: Madrid, 2006.

BHABHA, Homi. O Local da Cultura. Tradução de Myriam Avila; Eliana Lourenço de Lima Reis e Glaucia Renate Gonçalves. Belo Horizonte, Editora UFMG, 1998.

CERTEAU, Michel de. A invenção do cotidiano. Rio de Janeiro: Vozes, 1990.

CUNHA, Luiz Antonio. Ensino Superior e Universidade no Brasil. 2a. Edição. In LOPES, Eliane Marta Teixeira e FILHO, Luciano Mendes de Faria, VEIGA, Cynthia Greive. 500 anos de Educação no Brasil. Belo Horizonte: Autêntica, 2000.

DE DIEGO, Estrella. Travessías por la incertidumbre. Editorial Seix Barral, S. A. Barcelona, 2008.

FANON, Frantz. Piel Negra, máscaras blancas. Ediciones Akal, S.A.Madrid, 2009.

GUIMARÃES, Leda. Metáforas para o ensino de artes visuais na modalidade EAD. Licenciatura em Artes Visuais: módulo introdutório. UFG/FAV/CIAR. Goiânia: CEGRAF/UFG, 2008.

GUIMARÃES, Leda. Deslocamentos na formação de professores de artes visuais na modalidade a distância. In GORDILHO, Viga (org.) ANAIS do $19^{\circ}$ Encontro da Associação Nacional de Pesquisadores em Artes Plásticas "Entre Territórios" Cachoeira - Bahia, 2010a.

GUIMARÃES, Leda. e OLIVEIRA, Ronaldo. Formação docente e estágio curricular em artes Visuais na modalidade de ensino a distancia: Entre a realidade e a possibilidade de se criar uma escola em expansão. 33a. ANPED - Caxambu -MG. 2010b.

GUIMARÃES, Leda. e GUIMARÃES, Alexandre. Cartografando representações docentes no espaço www. In: "Subjetividades, utopias e fabulações". Anais do $20^{\circ}$ Encontro da Associação Nacional de Pesquisadores em Artes Plásticas. Sheila Cabo Geraldo, Luiz Cláudio da Costa (orgs). - Rio de Janeiro: ANPAP, 2011.

SILVA, Tomaz Tadeu da. Documentos de identidade: uma introdução às teorias do currículo. Belo Horizonte: Autêntica, 2005.

SOUZA, Lynn Mario T. Menezes de. Hibridismo e tradução cultural em Bhabha. In: ABDALA JÚNIOR, Benjamin (org). Margens da cultura: mestiçagem, hibridismo \& outras misturas. São Paulo: Boitempo Editorial, 2004. P. 113-133. 
colonial intensifica a vigilância e coloca uma ameaça imanente

' Professora Adjunta da Faculdade de Artes Visuais da Universidade Federal de Goiás, Bolsita Capes (2012-2013)

ledafav@gmail.com

ii Professora Assistente da Faculdade de Artes Visuais da Universidade Federal de Goiás. Doutoranda da Universidad de Barcelona, Espanha.

lilianucker@gmail.com

Recebido em: 23/09/2013

Aprovado em: 15/10/2013 